\title{
Editorial
}

\section{Prophesy in Traumatic Brain Injury}

What is prognostication? It is the estimation of the possible outcomes of treatment or a disease process. ${ }^{[1]}$ It is based on a combination of personal experience, statistics, and validated models. In most case scenarios, the prognostication is done on the basis of the clinician's view. A clinician's prognosis, stand alone has the disadvantage of inaccuracy, gut feeling, and multiple biases. In such situations, the prognostic models come in handy for a more accurate prognostication. These prognostic models are statistically developed with the inclusion of relevant prognostic factors to predict the risk of future clinical outcomes in patients. ${ }^{[2]}$

With increasing burden of traumatic brain injury (TBI) and its impact on the medical care expenses, prognostication of outcome is an important aspect to be considered in the management of such patients. There are concerning scenarios where decisions to withhold or withdraw life-sustaining treatment have to be taken. ${ }^{[3]}$ These decisions are usually made after considering the prognosis, the treating team's instinct and institutional and societal norms and values. The situation would be more difficult in the case of severe TBI because of the continuation of treatment often aids in the survival of patients for months to years but in a severely disabled state. Accurate information regarding the expected outcome is a requirement for the treating team to make an objective decision rather than deciding just based on instincts. This necessitates the development of reliable prognostic models for the prediction of outcome after TBI. A good prognostic model should have a high discriminative power. To the dismay of the neurosurgeon, there are more than 100 prognostic models available for TBI. Among them, there are two important prognostic models in relation to TBI, the CRASH, and the IMPACT models..$^{[4,5]}$ Although both the models are robust, the generalizability of these models is questionable. Still, the confusion in the treating clinician's mind would be whether to stick on to the basic scores such as the Glasgow Coma Scale (GCS) and the computed tomography (CT) scan findings or to depend on more comprehensive and multivariate prognostic models such as the IMPACT or the CRASH models.

The authors of the article "Simple scores for prognosis of TBI" have tried to answer the above pertinent question in their study. ${ }^{[6]}$ It is clinically very important to decide on which scores are to be used for prognostication. The study has to its advantage the large database to answer the objective. They have also chosen the commonly used scores in clinical practice the (GCS, GCS motor score [GCSM], the Abbreviated Injury Scale for the head region, the Marshall CT-classification and the Rotterdam CT-score). The other merit of the article is the comparison of the performance of the above-mentioned scores at different end-points with the IMPACT model. Accordingly, they observed that the simple scores were capable of predicting the prognosis but not to the extent of the more robust IMPACT model. The answer to their objective was clear that in their clinical setup and standard of trauma care, the more reliable prognostic model was the IMPACT model. The results are not surprising as the purpose of the multivariable model is to improve accuracy. A multivariable model can perform better that what an experienced human can predict. As the authors mentioned, the data set from two different time points is a drawback. As with IMPACT model, the authors' model is also based on the patient population over many years, which can have a potential to decrease accuracy as the care may have improved over years. Finally, the authors do not convince that a prognostic model based on simple variables is utilizable. The IMPACT model is indeed based on simple variables, which are routinely used in practice for management of severe TBI, the only difference is that the number of variables is more.

IMPACT and CRASH models are both well standardized with a large database, strong prediction models, and have been externally validated at multiple centers. These models have freely accessible web-based calculators which with the entry of the variables will give us the prognosis..$^{[4,5]}$ Although everything seems to be favorable for the usage, these prognostic models in the TBI prognostication, they do face a serious setback when it comes to its ease of application at the field level. These models demand the use of a large and strictly defined set of prognostic factors. This limits their feasibility to well-designed research studies and few clinical settings. Although it has been more than 7 years since these models have been available for use, they have not yet found their way to the emergency services of neurotrauma care, especially in developing countries. These demerits of the IMPACT and CRASH models leave us with the question whether to stick to the simple scores. These robust prognostic models should be customized accordingly to be easily applicable to all emergency services of neurotrauma care centers. That would prove as a real success of the prognostic research work which has gone behind these models.

Akhil Deepika, Dhaval Shukla Department of Neurosurgery, NIMHANS, Bengaluru, Karnataka, India

\author{
Address for correspondence: Dr. Dhaval Shukla, \\ Department of Neurosurgery, NIMHANS, Bengaluru, \\ Karnataka, India. \\ E-mail: neurodhaval@rediffmail.com
}

\section{REFERENCES}

1. Riley RD, Hayden JA, Steyerberg EW, Moons KG, Abrams K, Kyzas PA, et al. Prognosis research strategy (PROGRESS) 2: Prognostic factor research. PLoS Med 2013;10:e1001380.

2. Steyerberg EW, Moons KG, van der Windt DA, Hayden JA, Perel P, Schroter S, et al. Prognosis research strategy (PROGRESS) 3: Prognostic model research. PLoS Med 2013;10:e1001381.

3. Sise MJ, Sise CB, Thorndike JF, Kahl JE, Calvo RY, Shackford SR. Withdrawal of care: A 10-year perspective at a level I trauma center. J Trauma Acute Care Surg 2012;72:1186-93.

4. MRC CRASH Trial Collaborators, Perel P, Arango M, Clayton T, Edwards P, Komolafe E, et al. Predicting outcome after traumatic brain injury: Practical prognostic models based on large cohort of international patients. BMJ 2008;336:425-9. 
5. Steyerberg EW, Mushkudiani N, Perel P, Butcher I, Lu J, McHugh GS, et al. Predicting outcome after traumatic brain injury: Development and international validation of prognostic scores based on admission characteristics. PLoS Med 2008;5:e165.

6. Majdan M, Brazinova A, Rusnak M, Leitgeb J. Outcome prediction after traumatic brain injury: Comparison of the performance of routinely used severity scores and multivariable prognostic models. J Neurosci Rural Pract 2017;8:20-9.

This is an open access article distributed under the terms of the Creative Commons Attribution-NonCommercial-ShareAlike 3.0 License, which allows others to remix, tweak, and build upon the work non-commercially, as long as the author is credited and the new creations are licensed under the identical terms.

\begin{tabular}{|l|l|}
\hline \multicolumn{2}{|c|}{ Access this article online } \\
\hline Quick Response Code: & Website: \\
\hline & www.ruralneuropractice.com \\
& \\
& \\
\end{tabular}

How to cite this article: Deepika A, Shukla D. Prophesy in traumatic brain injury. J Neurosci Rural Pract 2016;7:S1-2. 